\title{
Injury incidence and distribution in elite football - a prospective study of the Danish and the Swedish top divisions
}

\author{
Martin Hägglund, Markus Waldén and Jan Ekstrand
}

\section{Linköping University Post Print}

\section{Tweet}

N.B.: When citing this work, cite the original article.

Original Publication:

Martin Hägglund, Markus Waldén and Jan Ekstrand, Injury incidence and distribution in elite football - a prospective study of the Danish and the Swedish top divisions, 2005, Scandinavian Journal of Medicine and Science in Sports, (15), 1, 21-28.

http://dx.doi.org/10.1111/j.1600-0838.2004.00395.x

Copyright: Wiley

http://eu.wiley.com/WileyCDA/

Postprint available at: Linköping University Electronic Press

http://urn.kb.se/resolve?urn=urn:nbn:se:liu:diva-14340 


\title{
Injury Incidence and Distribution in Elite
}

\section{Football: A Prospective study of the Danish and}

\author{
the Swedish Top Divisions.
}

Martin Hägglund PT

Markus Waldén MD

Jan Ekstrand MD, PhD

From the Department of Health and Society, Division of Social Medicine and Public Health

Science, Linköping University, Linköping, Sweden

Key words: sports injuries; soccer; incidence; epidemiology, re-injury.

Address for correspondence:

Martin Hägglund PT

Sports Clinic, Solstigen 3, S-58943 Linköping, Sweden.

E-mail: hagglund.martin@telia.com

Telefax: +44 13351112 . 


\section{ABSTRACT}

The Danish and Swedish male top football divisions were studied prospectively from January to June 2001. Exposure to football and injury incidence, severity and distribution were compared between the countries.

Swedish players had greater exposure to training (171 vs. $123 \mathrm{~h} /$ season, $\mathrm{p}<0.001$ ), whereas exposure to matches did not differ between the countries. There was a higher risk for injury during training in Denmark than in Sweden $(11.8$ vs. 6.0/1000 h, p<0.01), whereas for match play there was no difference (28.2 vs. 26.2/1000 h). The risk for incurring a major injury (absence from football more than four weeks) was greater in Denmark (1.8 vs. 0.7/1000 h, $\mathrm{p}=0.002)$. The distribution of injuries according to type and location was similar in both countries. Overuse injury accounted for 39 and $38 \%$ (ns), and re-injury for 30 and $24 \%$ $(\mathrm{p}=0.032)$ of all injuries in Denmark and Sweden respectively.

The greater training exposure, and the long pre-season period in Sweden, may explain some of the reported differences. 


\section{INTRODUCTION}

Several authors have studied the pattern of injury in football (Inklaar, 1994; Dvorak \& Junge, 2000). Studies on injuries in elite football show that players run a great risk for injury, with between 65 and 91\% of the players incurring an injury during a season (Lewin, 1989;

Engström, Forssblad, Johansson, Törnkvist, 1990; Árnason, Gudmundsson, Dahl, Jóhannsson, 1996; Lüthje et al., 1996; Hawkins \& Fuller, 1998; Hawkins \& Fuller, 1999; Hawkins, Hulse, Wilkinson, Hodson, Gibson, 2001, Hägglund, Waldén, Ekstrand, 2003).

Previous investigations from Sweden and Denmark on male adults have studied players at amateur and semi-professional levels (Ekstrand, 1982; Nielsen \& Yde, 1989; Engström et al., 1990; Ekstrand \& Tropp, 1990; Poulsen, Freund, Madsen, Sandvej, 1991). Nowadays players in the Swedish and Danish top divisions are full-time professionals, and injuries that may occur whilst playing football constitute an occupational hazard for the players.

Due to inconsistencies in study design and the definition of injury, it is difficult to compare results between different studies. Any differences in injury incidence or injury pattern between countries may be caused by methodological differences rather than an actual difference in injury panorama. In one study on youth level football, no substantial difference in injury incidence or injury distribution was found between players from two different European regions (Junge, Chomiak, Dvorak, 2000). However, we have not been able to find any studies that compare the injury risk for elite adult football players from different countries. 
The playing conditions in the Swedish First Division and the Danish Super league are comparable in most ways, however the disposition of the football season in Denmark and Sweden differs. The Danish season follows the traditional western European season, from Autumn to Spring, whereas the season in Sweden ranges from Spring to Autumn.

The purpose of this study was to examine the exposure to football and injury incidence, severity and distribution in male professional football in Sweden and Denmark. Our hypothesis was that there would be no difference between the two countries. 


\section{MATERIALS AND METHODS}

\section{Study period and subjects}

Using a cohort study design, the Danish male Super league (highest domestic level of competition) was followed prospectively during the Spring season (January to June) of 2001. The Spring season study period included a mid-season break in January and February, and the second half of the competitive season from March to June. All 12 teams in the Danish Super league were invited to participate in the study. Three teams were unable to comply with the practical demands of the study and did not consent to participation. One team provided insufficient data and was excluded. A total of 188 players from eight teams (range 20-28 players/team) were included. All players in the eight teams accepted participation.

Using the same cohort study design, all 14 teams in the Swedish male First Division (highest domestic level of competition) were followed for the full football season (January to October) of 2001. The study period included pre-season from January to March, and competitive season from April to October. Of the total 312 players, 310 players accepted participation (range 18-25 players/team) and were included in the study. One player did not consent to participation prior to start of the study and one player withdrew after three months.

Anthropometric data of the players included are presented in Table 1.

\section{Study procedure}

All first team players during the first study month (January) were included in the study; players contracted to the teams after January were not included. Players who were injured at the start of the study were included, their present injuries, however, were not counted. All 
players were informed about the study by their team physician, and signed informed consent obtained.

Each team kept attendance records for all training sessions and matches on a standardised form. Exposure to football (training and matches separately) was recorded in minutes for each player. Training and matches with the second or youth team, as well as national teams, were included. A training session was defined as any coach-directed scheduled physical activity carried out with the team.

\section{Injury definitions and severity}

The club medical staff (consisting of physician and physiotherapist or naprapath) diagnosed all injuries that occurred during the study period. An injury was defined according to Ekstrand (1982) as any injury occurring during a scheduled training session or match causing the player to miss the next training session or match. A standardised injury card was filled in for all injuries immediately after injury. The injury card contained information about the date of injury, scheduled activity (i.e. training session or match), type and location, whether it was a re-injury and, for match injuries, whether the injury was caused by a foul (according to the referee). A re-injury was defined as an identical injury of the same type and location within two months of the final rehabilitation day of the previous injury. Injuries were categorised as overuse or traumatic injuries. The definition of overuse injury was modified from Orava (1980) and defined as a pain syndrome of the musculoskeletal system with insidious onset and without any known trauma or disease that might have given previous symptoms (e.g. tendinosis, shin splints, stress fractures etc.). Traumatic injuries were characterised by an acute onset, the different injury types are displayed in Table 2. 
Injuries were classified into four severity categories according to the length of absence from training sessions and matches: slight (1-3 days), minor (4-7 days), moderate (8-28 days) and major (>28 days), including the day of injury. The number of days of absence was calculated according to the calendar. An injured player was defined injured until the club medical staff cleared him for participation in full training or match play. A player who performed alternative training or participated in only a part of the training session (e.g. during rehabilitation after an injury, or due to a pain syndrome) was considered injured.

Attendance records and injury cards were continuously sent in to the authors during the study period. To reduce bias in the data collection, all clubs received a manual containing information about the study design and definitions, including fictive examples and scenarios, prior to the study.

\section{Dropouts}

In Denmark, 11 players (6\%) dropped out during the study period (January to June), eight due to player transfer, two stopped playing football because of injury, and one player quit football due to illness. Sixteen players in the Swedish group (5\%) dropped out during the Spring season (January to June), 14 due to player transfer and two players were downgraded to the youth team. Data from players who dropped out during the study are included in the analyses for their entire time of participation.

\section{Calculation of exposure and injury incidence}

The mean numbers of training sessions and matches were calculated at team level as well as for the individual player. Actual exposure to football was calculated for the individual player for training sessions and matches separately. Injury incidence was calculated for all injuries 
per 1000 hours of football (training + matches), as well as for training and match injuries per 1000 hours of training and match play separately. This was calculated at team level as "(the number of injuries per team/hours of exposure per team) x 1000”.

\section{Analyses}

Comparisons were made between the Spring seasons (January to June) in Denmark and Sweden. Due to the different seasonal disposition in Denmark and Sweden, additional analyses were carried out between the Spring season in Denmark and the Autumn season (July to October) in Sweden, including the end of the competitive season.

Groups were compared for qualitative variables with the chi-square test, or the Fisher's exact test for small numbers. Quantitative variables were compared between groups using Student's t-test or the Mann-Whitney U-test in case of heterogeneity of variance (F-ratio test) or a non normal distribution (Kolmogorov-Smirnov test) (Armitage \& Berry, 1994). The significance level was set at $p \leq 0.05$. Results are expressed as means with standard deviations (SD) and $95 \%$ confidence interval $(95 \% \mathrm{CI})$. 


\section{RESULTS}

The results presented are analyses between the Spring seasons in Denmark and Sweden unless otherwise stated. Additional analyses between the Spring season in Denmark with the Autumn season in Sweden are presented in Tables 4-7.

\section{Exposure}

A total of 27321 hours of football were analysed in the Danish Super league from January to June, 23095 training hours and 4226 match hours. In Sweden, 59469 hours of football were analysed from January to June, 52910 training hours and 6559 match hours. The mean exposures to football are presented in Table 3. Swedish players had significantly greater exposure to training (171 vs. 123 hours/player, $\mathrm{p}<0.001$ ), whereas the exposure to match play did not differ between Sweden and Denmark. On average, Swedish players had 10.9 (SD 18.3) hours of training per match hour, compared to 6.6 (3.8) in Denmark ( $p<0.001)$. The mean (SD) training/match ratios (i.e. the number of training sessions/match) did not differ, with $5.6(1.7)$ and $6.7(0.7)$ for the teams in Denmark and Sweden respectively $(\mathrm{p}=0.16)$.

\section{Injury incidence and severity}

In Denmark, 153 players (81\%) incurred 395 injuries, 271 (69\%) training injuries and 124 (31\%) match injuries. In Sweden, 207 (67\%) players sustained 481 injuries, $313(65 \%)$ in training and $168(35 \%)$ in matches during the Spring season. There was a higher risk for injury during match play than during training in both countries. Table 4 displays the injury incidences in Denmark and Sweden. The injury incidence during training was higher in Denmark during the Spring season $(11.8$ vs. $6.0 / 1000$ hours, $\mathrm{p}<0.01)$, whereas during match 
play, there was no difference between the countries. Similar results were found for comparisons between the Spring season in Denmark and the Autumn season in Sweden.

The injury distribution according to severity is presented in Table 5. The majority of injuries were slight or minor, resulting in an absence of one week or less. There were 46 major injuries in Denmark and 41 in Sweden during the Spring season, comprising 12\% and 9\% of the total injuries. Major injuries were predominantly knee sprains (25\%), thigh strains (13\%) and overuse injuries to the groin (10\%). Danish players suffered more major injuries per 1000 hours of football during the Spring season (1.8 vs. 0.7, $\mathrm{p}=0.002)$. The mean (SD) number of days of absence per injury was 11.8 (20.5) and 13.1 (31.8) days for Denmark and Sweden respectively $(\mathrm{p}=0.078)$.

\section{Type and location of injuries}

The location of injuries was similar in Denmark and Sweden during the Spring season (Table $6)$, differing only in the proportion of knee injuries $(\mathrm{p}=0.032)$. The majority of injuries were located to the lower extremities, with 89 and $88 \%$ for Denmark and Sweden respectively. The thigh was the most frequent site of injury, followed by the knee and hip/groin region. The dominating injury diagnosis was thigh strain, being 58 of 395 injuries in Denmark (15\%) and 64 of 481 injuries in Sweden $(13 \%)$ during the Spring season $(\mathrm{p}=0.56)$.

Table 7 displays the distribution of injuries according to type. Overuse injury was the most common injury type, commonly affecting the groin, knee and lower leg. Overuse injuries were most common during training. The mean (SD) incidence of overuse injury was 5.6 (4.4) and $3.1(2.3) / 1000$ hours of football for Denmark and Sweden respectively $(\mathrm{p}=0.15)$. 
Strain was the most frequent traumatic injury, mainly affecting the thigh and groin. Overall, the mean (SD) incidence of strain was higher in Denmark [3.0 (1.8) vs. 1.7 (1.2)/1000 hours of football] $(\mathrm{p}=0.041)$.

Sprains were most common in the ankle and knee joints, the mean (SD) incidence being 3.0 (1.1)/1000 hours of football in Denmark and $1.4(0.8)$ in Sweden $(\mathrm{p}=0.004)$.

Comparison of injury distribution according to location and type of injuries between the Spring season in Denmark and the Autumn season in Sweden showed a similar pattern.

\section{Re-injuries}

Thirty per cent (119/395) of injuries in Denmark and 24\% (114/481) in Sweden were reinjuries $(\mathrm{p}=0.032)$. Injuries classified as overuse injury or strain accounted for $70 \%(83 / 119)$ and $82 \%(93 / 114)$ of all re-injuries in Denmark and Sweden respectively. Seventeen of fortysix (37\%) major injuries in Denmark, and 10 of 41 (24\%) in Sweden, were preceded within two months by the same type of injury to the same location and were regarded as re-injuries $(\mathrm{p}=0.20)$

\section{Foul play}

Twenty per cent (24/123) of the match injuries in Denmark and 21\% (35/168) in Sweden were caused by foul play according to the referee $(\mathrm{p}=0.78)$. The injured player was awarded the free kick in the majority of cases (22/24 and 32/35). 


\section{DISCUSSION}

The most significant finding in the present study was the higher injury incidence found during training in Denmark compared to Sweden. The study included prospectively recorded injuries and registration of individual exposure. Careful definition as to what constitutes an injury, an overuse injury, a re-injury, for how long the player is considered injured, what constitutes a training session etc. was employed to facilitate comparison with future studies. There are, however, a few methodological issues important to the interpretation of the results from this study.

\section{Methodological considerations}

The major limitation of the study is the short study period of six months. The teams in Sweden were followed during the whole football season, covering pre-season and competitive season. This is the ideal situation (Junge \& Dvorak, 2000; Ekstrand \& Karlsson, 2003). The teams in Denmark, however, were only followed during the second half of the season, including the finish of the competitive season. This is a weakness as the injury incidence and injury distribution have been found to vary over a season (Ekstrand \& Gillquist, 1983; Engström et al., 1990; Hawkins et al., 2001; Woods, Hawkins, Hulse, Hodson, 2002). To compensate for the shorter study period in Denmark, additional analyses were performed between the Spring season in Denmark and the Autumn season in Sweden. These analyses showed similar results. Nevertheless, the limited study period must be taken into account, also when comparing the results from the present investigation with other studies.

In the Swedish First division, the participation rate was excellent, with all 14 teams being included in the study. In Denmark, however, only nine of twelve invited teams accepted to 
participate in the study, and one further team provided insufficient data and was excluded. As a consequence, there is a risk for selection bias, and the Danish figures may be less representative of the total situation for Danish Super league teams. Participation and submitting data is always voluntary and, unfortunately, dropouts and insufficient data registration are common problems in epidemiological studies of sports injuries.

Inconsistencies in methodology make valid comparison between studies difficult, and many authors have emphasised the need for consensus in terms of study design, data collection and injury definition (van Mechelen, Hlobil, Kemper, 1992; Inklaar, 1994; Dvorak \& Junge, 2000). This study was preceded by discussions within the UEFA's (Union des associations européennes de football) medical committee about optimal study design (Ekstrand \& Karlsson, 2003). The injury definition used, i.e. time lost from football, has recently been criticised (Junge \& Dvorak, 2000). For instance, participation in training and matches may be affected by factors such as the medical availability of the team, importance of the match, player characteristics etc. Furthermore, the frequency of training sessions and matches influences the probability of a player missing a session due to injury. These factors should be taken into account, especially when comparing injury statistics between different levels of play or different countries. The professional football teams in the Swedish and the Danish top divisions have almost daily scheduled sessions, which minimize the chance of missing less severe injuries. In addition, the teams have medical personnel available at training sessions and matches increasing the likelihood of a proper diagnosis and treatment of injuries. To further increase the reliability of data collection, all clubs were provided with a manual of injury definitions, including fictive examples, prior to the study. 
The time lost definition has been recommended for studies of football injuries since it takes into account those injuries that are most likely to affect the player's health and performance. (Keller, Noyes, Buncher, 1987) To provide information on the seriousness of injuries, the injury severity was reported in terms of the length of absence from training sessions and matches. It is, thus, important to clarify for how long the player is considered injured and when he is fully rehabilitated. In this study, a player was defined injured until he was given clearance by the medical staff to participate fully in collective training sessions and matches.

\section{Exposure and injuries}

The Swedish teams had significantly more training during the Spring season. For the individual player, there were 39\% more hours of training in Sweden (171 vs. $123 \mathrm{~h}$ ), whereas no difference was found in match exposure. The different exposure was partly due to the fact that Swedish teams were followed during the pre-season period, during which time they train intensely. In Denmark, there was also a period of intense training in January and February, during the mid-season break, whereas from March to June the training rate dropped as the competitive season began.

The difference in exposure could possibly explain the higher injury incidence during training found in Denmark compared to Sweden (11.8 vs. 6.0/1000 h). Danish players had a more unfavourable training/match exposure ratio. It has previously been shown on amateur level that a high training/match-ratio is advantageous (Ekstrand, Gillquist, Möller, Öberg, Liljedahl, 1983), and it is fair to assume that this is also true at elite level. In the same study on amateur level, a lower incidence of traumatic injuries was found for teams with an above average amount of training (Ekstrand et al., 1983). The authors attributed this to better oxygen uptake, improved coordination, greater strength etc. for these players. To our knowledge, this 
relationship has not been verified in other studies. However, is seems to support the claim that a well-trained athlete sustains fewer injuries.

The greater training exposure may also have an effect on the amount of re-injuries. The physical, physiological and mental demands on the player is often higher during match play, probably reflecting the overall higher injury incidence found during match play. With a greater amount of training sessions in between matches, the medical staff and coaches have sufficient time for pre-match play clinical and functional testing of the injured player, which may reduce the risk for recurrence of injury.

\section{Seasonal disposition and injuries}

Another reason for the different injury incidences between the countries may be found in the seasonal disposition. Denmark and most of the countries in Europe have a season that ranges from Autumn to Spring. In Denmark there is a short four-week pre-season period prior to the start of the competitive season in the end of July. There is an additional mid-season break, with focus on training, from late December to February before the second half of the competitive season begins in March. The season in Sweden differs from the western European season, ranging from Spring to Autumn. This results in an unusually long pre-season period of 12 to 16 weeks, generally starting in December and lasting until the end of March.

Many teams devote the pre-season period to specific training aimed at strengthening tissues and enhancing technique and coordination, as it is commonly believed that this cause players to be less susceptible to injuries. In a study on elite male football players in Iceland, Árnason et al. (1996) found that teams with the longest pre-season period had fewer injuries during the season. Hawkins et al. (2001) recently discussed disadvantages with the short pre-season 
period for English professionals. The authors found a peak in match injuries at the start of the competitive season in August, and voiced a concern that players may not have reached optimal physical and physiological states at that time. It is possible that the longer continuous pre-season period in Sweden is favourable, as there is sufficient time to increase the players' level of fitness before the competitive season. However, this theory has to be verified in future studies.

\section{Injury incidence and severity}

Previous studies on injuries in elite football with similar definition of injury have reported incidences of between 1.8 to 5.9 injuries/1000 hours of training (Engström et al., 1990; Ekstrand \& Tropp, 1990; Árnason et al., 1996; Lüthje et al., 1996; Hawkins \& Fuller, 1999), comparable to the Swedish players in this study. Danish players had the highest reported injury incidence during training so far to our knowledge. However, it is difficult to say whether this is an effect of the different data collection methods and study procedures used or if it represents an actual difference in injury incidence. Injury incidences during match play were similar in Sweden and Denmark, and are within the range of previous reports from elite football (11.3 to 34.8/1000 hours of match play).

The majority of injuries amongst the Danish and Swedish professional football players resulted in absence from football of one week or less. This is in accordance with one previous study on Swedish male amateurs (Ekstrand \& Gillquist, 1983), whereas studies on Swedish and English elite players have reported a greater proportion of moderate and major injuries (Engström et al., 1990; Hawkins et al., 2001). Accounting for risk exposure, there were more major injuries per 1000 hours of football in Denmark compared to Sweden in this study, the 
incidence being fairly constant between the Spring and Autumn seasons in Sweden. The reasons for this difference are unclear, but may also be influenced by the different exposures.

\section{Type and location of injuries}

Almost two of five reported injuries were overuse injuries. Previous studies from Sweden and Denmark have reported similarly high proportions, 31-37\%, of overuse injuries (Ekstrand \& Gillquist, 1983; Nielsen \& Yde, 1989; Engström et al., 1990; Poulsen et al., 1991), possibly reflecting the sometimes poor environmental and surface conditions in northern Europe. However, other studies from countries with similar climate conditions showed lower amounts (2-9\%) of overuse injuries (Lüthje et al., 1996; Árnason et al., 1996; Hawkins \& Fuller, 1999; Hawkins et al., 2001). Most studies either lack a definition, or employ different definitions of what constitutes an overuse injury making valid comparison between studies difficult. In future studies, attention should be directed towards the amount and type of training that elite football players are exposed to. The role of fitness programmes in the prevention of overuse injuries, and the relationship between different surface and weather conditions and the development of overuse injuries needs further investigation.

Injuries categorised as strains or sprains were the most common traumatic injuries, each one comprising of one of five injuries in both Denmark and Sweden. The amount of sprains is consistent with the findings of Hawkins \& Fuller (1999) (20\%) and Hawkins et al. (2001) (19\%) for English professional footballers. Strains, however, were more common in these studies with approximately two of five injuries being categorised as muscle strains (Hawkins \& Fuller, 1999; Hawkins et al., 2001). The authors attributed the high rate of muscle strains to a possible negligence of general body conditioning and warm up and cool down programmes, as well as a lack of awareness of the benefits of injury prevention strategies. Accounting for 
risk exposure, there were almost twice as many strains in Denmark than in Sweden during the Spring season. The long pre-season, providing plenty of time for strength and fitness programmes, in Sweden may be an advantage as discussed previously. The benefits of eccentric strength training during pre-season for hamstrings strains have recently been shown in a randomised study on Swedish male elite players (Askling, Karlsson, Thorstensson, 2003).

Previous investigations have reported ankle injuries to be the most common injury in football (Ekstrand, 1982; Nielsen \& Yde, 1989; Poulsen et al., 1991). We found that the thigh was the most common injury location, in accordance with the results from studies on English professionals (Hawkins \& Fuller, 1999; Hawkins et al., 2001). Whether this represents an actual decrease in ankle injuries and an increase in thigh injuries, especially thigh strains, in recent years have to be verified in future studies.

\section{Re-injuries}

Thirty and twenty-four per cent of the injuries in Denmark and Sweden were re-injuries. This is within the range of what has been reported from most studies, where 22 to $42 \%$ were reinjuries (Nielsen \& Yde, 1989; Engström et al., 1990; Árnason et al., 1996; Hawkins \& Fuller, 1999). Hawkins et al. (2001) reported only 7\% re-injuries for English professional footballers, however, the definition of a re-injury is not clear in this study.

Thirty-seven per cent of the major injuries in Denmark and 24\% in Sweden were regarded as re-injuries. Inadequate rehabilitation and premature return to play after injury have been suggested as risk factors for recurrence of injury in previous studies. Ekstrand \& Gillquist (1983) reported that $35 \%$ of moderate and major injuries were preceded by a minor injury within two months. The authors attributed this to inadequate rehabilitation and premature 
return to play. Similarly, poor treatment and short rehabilitation time has been suggested to be risk factors for incurring a severe injury (Chomiak, Junge, Peterson, Dvorak, 2000). The authors stated that $24 \%$ of the major injuries had been preceded within three months by an injury to the same location. The relationship between rehabilitation time and re-injuries in football needs to be evaluated further. However, it seems that less severe injuries should not be neglected as they may predispose the player to incurring new, and perhaps more severe, injury.

\section{Conclusions}

The purpose of this study was to compare exposure and injury statistics between the Danish and the Swedish male top divisions. Swedish players had a greater training exposure, due to the intense training during pre-season. There is a high risk for injury in elite football, the injury risk being three to five times higher during match play than during training sessions. Players in Denmark had a higher risk for injury during training, and a higher recurrence rate of injuries than their colleagues in Sweden. Furthermore, the risk of incurring a major injury was more than twice as high in Denmark. The greater training exposure, and the longer preseason period in Sweden, may explain some of the reported differences. 


\section{PERSPECTIVES}

This was the first study to compare injury incidence and distribution between professional football players in two different countries. The results from the present study showed that the location and types of injuries vary little between Denmark and Sweden. The most common injury site was the thigh, predominantly muscle strains, similar to recent studies on English professionals (Hawkins \& Fuller, 1999; Hawkins et al., 2001). Injuries categorised as overuse or strain comprised 60\% of all injuries for the professional players in Denmark and Sweden. Many of these injuries, especially thigh strains and overuse injury to the groin, cause substantial absence from football. The contribution of weather and surface variables in the development of these common injuries needs to be investigated further. The benefits of eccentric training for the hamstrings have recently been reported in a randomised study on Swedish elite players (Askling et al., 2003). The authors found a lower occurrence of muscle strain injuries to the hamstrings in the intervention group who received a 10 -week training programme during pre-season. The potential role of fitness end strength training in the prevention of overuse injuries should also be evaluated. 


\section{Acknowledgements}

The authors gratefully acknowledge

UEFA (Union des associations européennes de football), SvFF (Swedish Football Association) and the Swedish Sports Confederation (Sports Research Council) for financial support of the study.

Mogens Kreutzfeldt MD (Danish Football Association), Ulrich Fredberg MD and Christen Villberg MD (Association of Danish Football Team Physicians) as well as Marie Lundberg and Torbjörn Segerberg for valuable assistance with the data collection.

All the club physicians and contact persons, for collection of exposure and injury data, as well as all the players and coaches for their participation in the study.

Statistician Nadine Karlsson for statistical advice and Peter Cox, MD, for correcting the vocabulary. 


\section{REFERENCES}

Armitage P, Berry G. Statistical methods in medical research. 3rd ed. Oxford: Blackwell, 1994.

Árnason Á, Gudmundsson Á, Dahl HA, Jóhannsson E. Soccer injuries in Iceland. Scand J Med Sci Sports 1996: 6: 40-45.

Askling C, Karlsson J, Thorstensson A. Hamstring injury occurrence in elite soccer players after preseason strength training with eccentric overload. Scand J Med Sci Sports 2003: 13 (4): 244-250.

Chomiak J, Junge A, Peterson L, Dvorak J. Severe injuries in football players. Influencing factors. Am J Sports Med 2000: 28 (Suppl): S58-S68.

Dvorak J, Junge A. Football injuries and physical symptoms: A review of the literature. Am J Sports Med 2000: 28 (Suppl.): S3-S9.

Ekstrand J. Soccer injuries and their prevention (Thesis) 1982. Linköping, Sweden: Linköping University.

Ekstrand J, Gillquist J, Möller M, Öberg B, Liljedahl SO. Incidence of soccer injuries and their relation to training and team success. Am J Sports Med 1983: 11: 63-67.

Ekstrand J, Gillquist J. Soccer injuries and their mechanisms. A prospective study. Med Sci Sports Exerc 1983: 15: 267-270.

Ekstrand J, Tropp H. The incidence of ankle sprains in soccer. Foot \& Ankle 1990: 11 (1): 4144.

Ekstrand J, Karlsson J. The risk for injury in football. There is a need for a consensus about definition of the injury and the design of studies. Scand J Med Sci Sports 2003: 13: 147149. 
Engström B, Forssblad M, Johansson C, Törnkvist H. Does a major knee injury definitely sideline an elite soccer player? Am J Sports Med 1990: 18 (1): 101-105.

Hawkins RD, Fuller CW. An examination of the frequency and severity of injuries and incidents at three levels of professional football. Br J Sports Med 1998: 32: 326-332.

Hawkins RD, Fuller CW. A prospective epidemiological study of injuries in four English professional football clubs. Br J Sports Med 1999: 33: 196-203.

Hawkins RD, Hulse MA, Wilkinson C, Hodson A, Gibson M. The association football medical research programme: an audit of injuries in professional football. Br J Sports Med 2001: $35: 43-47$.

Hägglund M, Waldén M, Ekstrand J. Exposure and injury risk in Swedish elite football: a comparison between seasons 1982 and 2001. Scand J Med Sci Sports 2003: 13: 364-370.

Inklaar H. Soccer injuries. I: Incidence and severity. Sports Med 1994: 18 (1): 55-73.

Junge A, Dvorak J. Influence of definition and data collection on the incidence of injuries in football. Am J Sports Med 2000: 28 (Suppl): S40-S46.

Junge A, Chomiak J, Dvorak J. Incidence of football injuries in youth players. Comparison of players from two European regions. Am J Sports Med 2000: 28 (Suppl): S47-S50.

Keller CS, Noyes FR, Buncher CR. The medical aspects of soccer injury epidemiology. Am J Sports Med 1987: 15 (3): 272-274.

Lewin G. The incidence of injury in an English professional soccer club during one competitive season. Physiother 1989: 75 (10): 601-605.

Lüthje P, Nurmi I, Kataja M, Belt E, Helenius P, Kaukonen JP, Kiviluoto H, Kokko E, Lehtipuu TP, Lehtonen A, Liukkonen T, Myllyniemi J, Rasilainen P, Tolvanen E, Virtanen H, Walldén M. Epidemiology and traumatology of injuires in elite soccer: a prospective study in Finland. Scand J Med Sci Sports 1996: 6: 180-185. 
Nielsen AB, Yde J. Epidemiology and traumatology of injuries in soccer. Am J Sports Med 1989: 17 (6): 803-807.

Orava S. Excertion injuries due to sports and physical exercise. A clinical and statistical study of nontraumatic overuse injuries of the musculoskeletal system of athletes and keep-fit athletes (Thesis) 1980. Kokkola, Finland.

Poulsen TD, Freund KG, Madsen F, Sandvej K. Injuries in high-skilled and low-skilled soccer: a prospective study. Br J Sports Med 1991: 25 (3): 151-153.

van Mechelen W, Hlobil H, Kemper H. Incidence, severity, aetiology and prevention of sports injuries. A review of concepts. Sports Med 1992:14:82-99.

Woods C, Hawkins R, Hulse M, Hodson A. The Football Association medical research programme: an audit of injuries in professional football - analysis of preseason injuries. Br J Sports Med 2002: 36: 436-441. 


\section{FIGURES AND LEGENDS}

Table 1

Anthropometric data of male elite football players in Denmark and Sweden.

Table 2

Classification of traumatic injury types.

Table 3

Exposure to football during the Spring seasons (January to June) in Denmark and Sweden.

Means with standard deviations (SD) and 95\% confidence interval (95\% CI).

Table 4

Injury incidences in Denmark and Sweden. Means with standard deviations (SD) and 95\% confidence interval $(95 \% \mathrm{CI})$.

\section{Table 5}

Severity of injuries according to absence from training sessions and matches in Denmark and Sweden.

Table 6

Location of injuries.

Table 7

Type of injuries. 
Table 1. Anthropometric data of male elite football players in Denmark and Sweden.

\begin{tabular}{|c|c|c|c|c|c|c|c|}
\hline & \multicolumn{3}{|c|}{ Denmark $(\mathrm{N}=188)$} & \multicolumn{4}{|c|}{ Sweden $(\mathrm{N}=310)$} \\
\hline & Mean & (SD) & (Range) & Mean & (SD) & (Range) & $\mathrm{P}$-value \\
\hline Age (years) & 26 & (4) & $(17-37)$ & 25 & $(5)$ & $(17-38)$ & 0.027 \\
\hline Weight (kg) & 79 & (6) & $(61-95)$ & 79 & (6) & $(62-98)$ & 0.74 \\
\hline Length $(\mathrm{cm})$ & 183 & (5) & $(167-195)$ & 182 & (6) & $(168-198)$ & 0.036 \\
\hline
\end{tabular}

Table 2. Classification of traumatic injury types.

\begin{tabular}{ll}
\hline Injury type & Classification \\
\hline Contusion & Tissue bruise without concomitant injuries classified elsewhere \\
Dislocation & Partial or complete displacement of the bony parts of a joint \\
Fracture & Traumatic break of bone \\
Other & Injuries not classified elsewhere (e.g. wounds, concussions etc) \\
Sprain & Distraction injury of ligaments or joint capsules. Cartilage and meniscus lesions \\
Strain & Distension injury of muscles and tendons \\
\hline
\end{tabular}

Table 3. Exposure to football during the Spring seasons (January to June) in Denmark and Sweden. Means with standard deviations (SD) and 95\% confidence interval (95\% CI).

\begin{tabular}{|c|c|c|c|c|c|}
\hline & \multicolumn{2}{|c|}{$\begin{array}{l}\text { Denmark } \\
\text { Spring season }\end{array}$} & \multicolumn{3}{|c|}{$\begin{array}{l}\text { Sweden } \\
\text { Spring season }\end{array}$} \\
\hline & Mean (SD) & $(95 \% \mathrm{CI})$ & Mean (SD) & $(95 \% \mathrm{CI})$ & P-value \\
\hline \multicolumn{6}{|c|}{ Training sessions ${ }^{1}$} \\
\hline -No./team & $120(16)$ & $(106,133)$ & $153(11)$ & $(146,160)$ & $<0.001$ \\
\hline -No./player & $84(30)$ & $(80,88)$ & $118(32)$ & $(115,122)$ & $<0.001$ \\
\hline \multicolumn{6}{|l|}{ Matches $^{2}$} \\
\hline -No./team & $23(5)$ & $(18,27)$ & $23(2)$ & $(22,24)$ & 0.97 \\
\hline -No./player & $16(7)$ & $(15,17)$ & $17(6)$ & $(16,17)$ & 0.52 \\
\hline \multicolumn{6}{|l|}{ Exposure $^{3}$} \\
\hline -Total & $145(51)$ & $(138,153)$ & $192(52)$ & $(186,198)$ & $<0.001$ \\
\hline -Training & $123(44)$ & $(117,129)$ & $171(45)$ & $(166,176)$ & $<0.001$ \\
\hline -Matches & $22(11)$ & $(21,24)$ & $21(9)$ & $(20,22)$ & 0.23 \\
\hline
\end{tabular}

${ }^{1}$ Number of training sessions per team and per player.

${ }^{2}$ Number of matches per team and per player.

${ }^{3}$ Hours of exposure per player. 


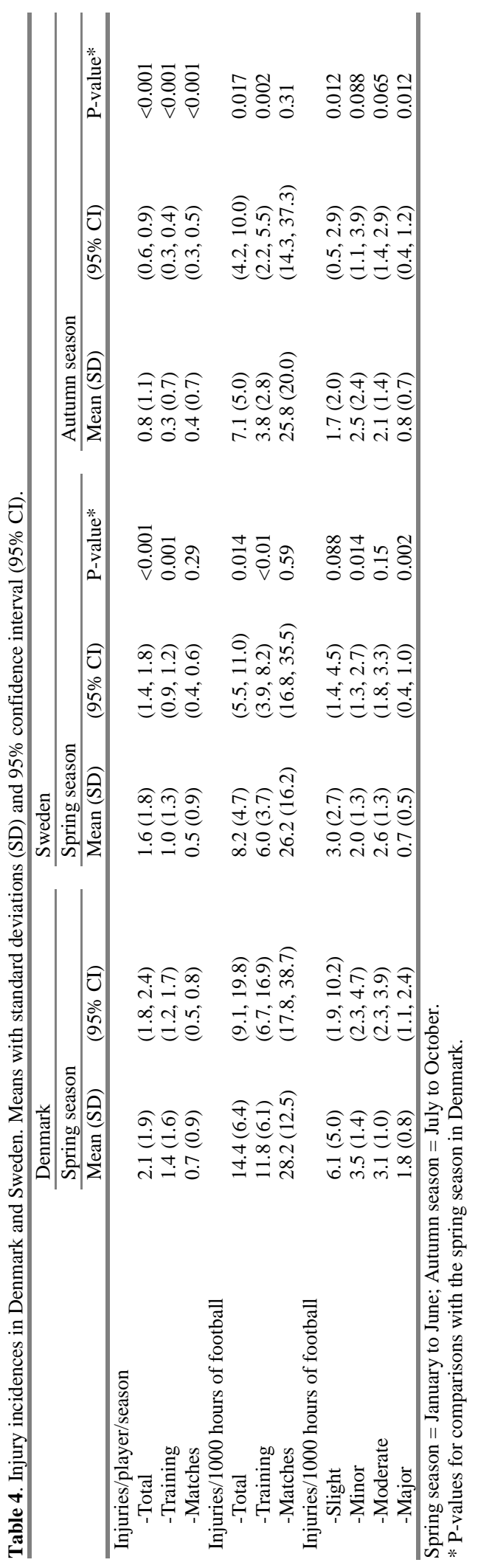


Table 5. Severity of injuries according to absence from training sessions and matches in Denmark and Sweden.

\begin{tabular}{|c|c|c|c|c|c|c|}
\hline & \multirow{2}{*}{\multicolumn{2}{|c|}{$\begin{array}{l}\text { Denmark } \\
\text { Spring season }\end{array}$}} & \multicolumn{4}{|c|}{ Sweden } \\
\hline & & & \multicolumn{2}{|c|}{ Spring season } & \multicolumn{2}{|c|}{ Autumn season } \\
\hline & $\mathrm{N}$ & $\%$ & $\mathrm{~N}$ & $\%$ & $\mathrm{~N}$ & $\%$ \\
\hline Slight (1-3 days) & 170 & 43 & 175 & $36^{*}$ & 58 & $25 * * *$ \\
\hline Minor (4-7 days) & 96 & 24 & 115 & 24 & 81 & $35 * *$ \\
\hline Moderate (8-28 days) & 83 & 21 & 150 & $31 * * *$ & 69 & $29 *$ \\
\hline Major (>28 days) & 46 & 12 & 41 & 9 & 26 & 11 \\
\hline Total & 395 & 100 & 481 & 100 & 234 & 100 \\
\hline
\end{tabular}

Spring season = January to June; Autumn season = July to October.

Significantly different from Denmark at: $* \mathrm{p}<0.05 ; * * \mathrm{p}<0.01 ; * * * \mathrm{p}<0.001$.

Table 6. Location of injuries.

\begin{tabular}{|c|c|c|c|c|c|c|}
\hline & \multirow{2}{*}{\multicolumn{2}{|c|}{$\begin{array}{l}\text { Denmark } \\
\text { Spring season }\end{array}$}} & \multicolumn{4}{|c|}{ Sweden } \\
\hline & & & \multicolumn{2}{|c|}{ Spring season } & \multicolumn{2}{|c|}{ Autumn season } \\
\hline & $\mathrm{N}$ & $\%$ & $\mathrm{~N}$ & $\%$ & $\mathrm{~N}$ & $\%$ \\
\hline Thigh & 87 & 22 & 112 & 23 & 53 & 23 \\
\hline Knee & 81 & 21 & 72 & $15^{*}$ & 39 & 17 \\
\hline Hip/groin & 58 & 15 & 77 & 16 & 37 & 16 \\
\hline Ankle & 52 & 13 & 55 & 11 & 18 & $8 *$ \\
\hline Lower leg & 45 & 11 & 69 & 14 & 40 & $17 *$ \\
\hline Foot & 29 & 7 & 36 & 7 & 17 & 7 \\
\hline Back & 28 & 7 & 30 & 6 & 13 & 6 \\
\hline Head/face/neck & 3 & $<1$ & 9 & 2 & 7 & $3 *$ \\
\hline Other & 12 & 3 & 21 & 4 & 10 & 4 \\
\hline Total & 395 & 100 & 481 & $98^{1}$ & 234 & $101^{1}$ \\
\hline
\end{tabular}

Spring season = January to June; Autumn season = July to October.

Significantly different from Denmark at: $* \mathrm{p}<0.05$

${ }^{1}$ Results for totals may not agree with results for individual components due to approximation error.

Table 7. Type of injuries.

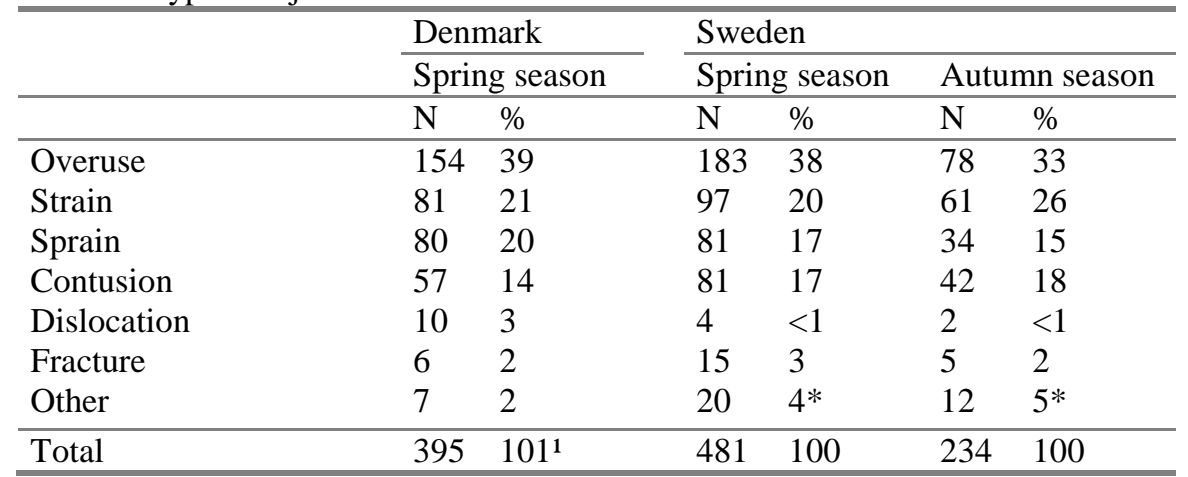

Spring season = January to June; Autumn season = July to October.

Significantly different from Denmark at: * $\mathrm{p}<0.05$

${ }^{1}$ Results for totals may not agree with results for individual components due to approximation error. 